\title{
The impact of exercise duration and intensity on the release of cardiac biomarkers
}

\author{
E. Serrano-Ostáriz ${ }^{1}$, J. L. Terreros-Blanco ${ }^{2}$, A. Legaz-Arrese ${ }^{1}$, K. George ${ }^{3}$, R. Shave ${ }^{4}$, P. Bocos-Terraz ${ }^{5}$, \\ S. Álvarez-Izquierdo ${ }^{5}$, J. L. Bancalero ${ }^{5}$, J. M. Echavarri ${ }^{2}$, J. Quilez ${ }^{2}$, M. T. Aragonés ${ }^{2}$, L. E. Carranza-García ${ }^{1}$ \\ ${ }^{1}$ Section of Physical Education and Sports, University of Zaragoza, Zaragoza, Spain, ${ }^{2}$ Sports Medicine Center, Aragón Government, \\ Zaragoza, Spain, ${ }^{3}$ Research Institute for Sport and Exercise Sciences, Liverpool John Moores University, Liverpool, UK, ${ }^{4}$ Centre for \\ Sports Medicine and Human Performance, Brunel University, Uxbridge, UK, ${ }^{5}$ Service of Biochemistry, Miguel Servet University \\ Hospital, Zaragoza, Spain \\ Corresponding author: E. Serrano-Ostáriz, Section of Physical Education and Sports, University of Zaragoza, C/Domingo \\ Miral, s/n-50009 Zaragoza, Spain. Tel: +349 767610 00, Fax: + 349767617 20, E-mail: enrise@unizar.es
}

Accepted for publication 17 August 2009

\begin{abstract}
Numerous studies have observed cardiac biomarker release with prolonged exercise. Despite this, we are unsure as to the constituent aspects of any given exercise bout that may be important in promoting cardiac biomarker release. This study examined the influence of exercise duration and intensity on the appearance of cardiac biomarkers. Twenty-one subjects ran for 45,90 and $180 \mathrm{~min}$ at $85 \%$ and $95 \%$ of their individual anaerobic threshold on six different days randomized. Cardiac troponin I (cTnI) and $\mathrm{N}$-terminal pro-brain natiuretic peptide (NT-proBNP) were assayed from blood samples collected before, $30 \mathrm{~min}$ and $3 \mathrm{~h}$ post-exercise. NT-proBNP was elevated
\end{abstract}

after all exercise trials (range before: 21-32; range post: $38-67 \mathrm{ng} / \mathrm{L})$. Peak post-exercise concentrations of NT-proBNP were associated with exercise duration $(P=0.049)$, but not exercise intensity $(P=0.451)$. cTnI was elevated after all exercise trials (range before: $0.007-$ 0.011; range post: $0.008-0.021 \mu \mathrm{g} / \mathrm{L}$ ). Peak post-exercise concentrations of $\mathrm{cTnI}$ were associated with exercise duration $(P=0.003)$ and intensity $(P=0.037)$. Data suggest that while both cTnI and NT-proBNP increased after all exercise trials, the mediating effect of duration influenced both NT-proBNP and cTnI while intensity influenced only cTnI.
An increasing number of studies have shown that prolonged strenuous exercise promotes the elevation of cardiac-specific biomarkers, troponins [cardiac troponin $\mathrm{T}(\mathrm{cTnT})$ and $\mathrm{cTnI}]$ and N-terminal probrain natiuretic peptide (NT-proBNP), known to serologically identify cardiac injury and dysfunction (Herrmann et al., 2003; Vidotto et al., 2005; Shave et al., 2007b; La Gerche et al., 2008). As a consequence, an intense debate has developed over the clinical repercussions for recreational athletes competing in long-distance events (Herrmann et al., 2003; Neilan et al., 2006; La Gerche et al., 2008). While most scientific literature has reported that cardiac biomarkers decrease to normal levels in the days following a competition (Herrmann et al., 2003; La Gerche et al., 2008), suggestive of a physiological response (Scharhag et al., 2005, 2006), three recent studies have shown an association between the increase in cardiac biomarkers and echocardiographic evidence of a reduction in cardiac function following completion of a marathon (Neilan et al., 2006) or an ultraendurance triathlon (Tulloh et al., 2006; La Gerche et al. 2008).
The awareness, and clinical interpretation, of exercise-related changes in cardiac-specific biomarkers is complicated by high inter-individual variation in available field-based competitive data (Shave et al., 2007b) that may be partially explained by large variations in exercise parameters such as duration and intensity. Field-based competitive studies are normally based on set distance courses (marathon, triathlon) and as such exercise duration and intensity are highly variable. On this basis, the influence, for example, of exercise duration on cardiac-specific biomarker release is poorly understood and controversial. Neilan et al. (2006) found that those runners with lower training experience showed the greatest increase in cTnT following a marathon race. Nevertheless, the authors did not report the correlation level between exercise duration and cTnT release. In contrast, Rifai et al. (1999) observed a significant inverse correlation between the race time in an Ironman event and post-race cTnT. In other individual competitions, exercise duration has not been associated with increases in cTnI or cTnT (Scharhag et al., 2005, 2006; George et al., 2004) but recently, a 


\section{Serrano-Ostáriz et al.}

meta-analysis reported that post-exercise cTnT values decreased slightly as the event duration increased (Shave et al., 2007b), which was speculated to be related to lower exercise intensities in ultraendurance events. Researches assessing cardiac-specific biomarkers in association the manipulation of exercise intensity and duration are not available. While the clinical significance of the increase in cardiac-specific biomarkers following strenuous endurance exercise in healthy athletes is unclear, the importance and role of factors that may promote biomarker release should be documented in wellcontrolled studies.

\section{Material and methods}

\section{Subjects and design}

Twenty-one runners, 19 males (age: $38 \pm 8$ years; height: $1.77 \pm 0.07 \mathrm{~m}$; body mass: $73.6 \pm 6.3 \mathrm{~kg} ; \mathrm{VO}_{2 \max }: 58.0 \pm$ $5.1 \mathrm{~mL} / \mathrm{kg} / \mathrm{min}$; training history: $11 \pm 8$ years, training volume: $75 \pm 35 \mathrm{~km} /$ week) and two females (age: $38.5 \pm 0.7$ years; height: $1.55 \pm 0.06 \mathrm{~m}$; body mass: $52.7 \pm 6.2 \mathrm{~kg}$; $\mathrm{VO}_{2 \max }$ : $49.3 \pm 3.9 \mathrm{~mL} / \mathrm{kg} / \mathrm{min}$; training history: $8 \pm 4$ years, training volume: $48 \pm 18 \mathrm{~km} /$ week), scheduled to participate in the 2008 Zaragoza marathon race, were recruited by an open invitation linked to the official web page for the race organization. After an initial meeting, where the aim and protocol of the research were explained, all subjects provided written informed consent. The study was approved by the Research Ethics Committee of the Government of Aragón (Spain).

To exclude acute or chronic diseases, an initial medical examination including recording the history of cardiac symptoms, resting blood pressure, electrocardiography and standard echocardiography was performed. In addition, a functional test for the determination of the maximum oxygen uptake $\left(\mathrm{VO}_{2 \max }\right)$ and parameters corresponding to the individual anaerobic threshold (IAT) was performed.

On 6 days separated by 1 week, and in a randomized order, athletes performed exercise trials of 45-, 90- and 180-min duration at intensities of $85 \%$ and $95 \%$ IAT on a natural circuit (distance: $4600 \mathrm{~m}$, maximum slope: $2 \%$ ). An intensity of $95 \%$ IAT was chosen as a representation of the maximal sustainable intensity for $3 \mathrm{~h}$ of exercise, and an intensity of $85 \%$ IAT as a submaximal intensity for each duration that would be completed at an heart rate (HR) significantly lower than the $95 \%$ IAT trial. This may be more akin to a training run. Intensities were determined by HRs and checked by HR monitoring of the submaximal bouts (Polar, Kempele, Finland). A maximum variation of \pm 2 beats $/ \mathrm{min}$ was allowed between the prescribed HR and the actual measured value. Venous blood samples to measure cardiac biomarkers were taken before, $30 \mathrm{~min}$ and $3 \mathrm{~h}$ after each exercise. Runners were advised to avoid strenuous exercise 2 days before each trial. All trials took place between May and June, with small variations in temperature $\left(16.8 \pm 2.0^{\circ} \mathrm{C}\right)$ and humidity $(67.7 \pm 10.0 \%)$.

\section{Exercise ergometry}

To determine the IAT using the method of Stegmann et al. (1981), incremental multistage treadmill ergometry (Laufergotest, Jaeger, Germany) was started at $8 \mathrm{~km} / \mathrm{h}$, and increased by $2 \mathrm{~km} / \mathrm{h}$ every $3 \mathrm{~min}$ until exhaustion. Capillary blood samples were taken from the hyperaemized earlobe at the end of each stage and 1, 3, 5, 7, 10 and 20 min after cessation of exercise to determine lactate concentrations (1500 sport YSI, Yellow Springs, Ohio, USA). In addition, a 12-lead ECG, blood pressure and $\mathrm{VO}_{2}$ (CPX/MAX MedGraphics, St. Paul, Minnesota, USA) were recorded.

\section{Cardiac-specific biomarkers}

Before and after all prolonged exercise trials, blood samples were drawn from an antecubital vein and collected in tubes. Samples were quickly centrifuged and the plasma was stored below $-80{ }^{\circ} \mathrm{C}$. NT-proBNP was measured by chemiluminescence on an automated analyzer (Elecsys proBNP; Elecsys 2010; Roche Diagnostics, Mannhein, Germany). The URL for NT-proBNP was considered to be $125 \mathrm{ng} / \mathrm{L}$ (Al-Barjas et al., 2004). cTnI was measured by chemiluminescence inmunoassays on automated analyzers (AccuTnI, Access; Beckman Coulter, Krefeld, Germany). The URL for cTnI, defined as the 99th percentile of healthy participants, was $0.04 \mu \mathrm{g} / \mathrm{L}$ (Apple et al., 2003).

\section{Statistical analysis}

Statistical analyses were performed using the Statistical Package of Social Sciences, version 15.0. Data are expressed as means with the corresponding standard deviations. Initially, to also assess the impact of measurement time (pre, $30 \mathrm{~min}$ and $3 \mathrm{~h}$ post), a repeated-measures three-way analysis of variance (ANOVA) was run on NT-proBNP and cTnI data. Consequently, two-way ANOVAs (duration and intensity) were performed on peak post-exercise concentrations of NTproBNP and cTnI data as well as exercise HR and distance covered. Post hoc Tukey tests were used where appropriate. In order to observe the presence of significance differences among the exercise trials in the percentage of subjects with postexercise cardiac biomarkers values that exceeded the URL, a comparison of the proportions was performed using a chisquared analysis. A multivariate linear regression was used to assess the relationships between the absolute and the relative exercise-related increase in cardiac biomarkers as dependent variables and baseline biomarker data, age, $\mathrm{VO}_{2 \max }$ and velocity at IAT as the independent predictors.

\section{Results}

\section{IAT test data, HR and distance covered}

The IAT was identified at $12.7 \pm 1.8 \mathrm{~km} / \mathrm{h}, \mathrm{HR}$ : $155 \pm 8$ beats $/ \min , \quad \% \mathrm{HR}_{\max }: \quad 85 \pm 6, \quad \% \mathrm{VO}_{2 \max }$ : $77 \pm 10$. HR at $95 \%$ and $85 \%$ of the IAT was established as $147 \pm 7$ beats/min $\left(82 \pm 3 \% \mathrm{HR}_{\max }\right)$ and $132 \pm 6$ beats $/ \min \left(73 \pm 3 \% \mathrm{HR}_{\max }\right)$, respectively. All runners were able to complete all exercise trials at the prescribed intensities. For HR during exercise (see Table 1), there was no significant effect of duration or a duration $\times$ intensity interaction $(P>0.05)$. As would be expected, HR was significantly altered by exercise intensity $(P=0.000)$. For distance covered during each exercise trial (Table 1), there was, as expected, a significant effect of duration $(P=0.000)$, intensity $(P=0.000)$ and interaction $(P=0.000)$. 
NT-proBNP and exercise duration and intensity

Pre-exercise values of NT-proBNP were not significantly different for all trials. From the three-way ANOVA, a significant main effect of assessment time (pre: $25.76 \mathrm{ng} / \mathrm{L}$; post $30 \mathrm{~min}: 51.59 \mathrm{ng} / \mathrm{L}$; post $3 \mathrm{~h}$ : $51.14 \mathrm{ng} / \mathrm{L} ; \quad P=0.000)$ confirmed an exercise response (Table 2). Analysis of peak responses postexercise detailed a significant main effect for duration of trail $(P=0.049)$ but no main effect of intensity $(P=0.451)$ or interaction $(P=0.810)$. Pre-exercise values NT-proBNP were below the URL of $125 \mathrm{ng} / \mathrm{L}$ in all participants. Post-exercise, there were no significant differences among the exercise trials in the percentage of subjects who exceeded the URL (range: 5-14\%). The exercise-related increases in NT-proBNP were independent of the age, training status, $\mathrm{VO}_{2 \max }$ and the other variables controlled in the study. In all exercise trials, the resting values of NT-proBNP were significantly correlated (Fig. 1) with the absolute post-exercise values $(r=0.87-$ $0.96, P=0.000)$ as well as with relative changes with exercise $(r=0.65-0.80, P=0.000)$.

\section{cTnl and exercise duration and intensity}

Pre-exercise values of cTnI were not significantly different for all trials. From the three-way ANOVA, a significant main effect of assessment time (pre: 0.008 ; post $30 \mathrm{~min}$ : 0.011 ; post $3 \mathrm{~h}: 0.013 \mu \mathrm{g} / \mathrm{L}$; $P=0.000$ ) confirmed an exercise response (Table $3)$. Analysis of peak responses post-exercise detailed significant main effects for duration $(P=0.003)$ and

Table 1. Mean exercise HR and distances covered in the exercise trials

\begin{tabular}{|c|c|c|c|c|}
\hline & \multicolumn{2}{|c|}{ HR (beats/min) } & \multicolumn{2}{|c|}{ Distance covered $(\mathrm{km})$} \\
\hline & $85 \%$ IAT & $95 \%$ IAT & $85 \%$ IAT & $95 \%$ IAT \\
\hline $\begin{array}{l}45 \mathrm{~min} \\
90 \mathrm{~min} \\
180 \mathrm{~min}\end{array}$ & $\begin{array}{l}132 \pm 7 \\
132 \pm 6 \\
133 \pm 7\end{array}$ & $\begin{array}{l}147 \pm 8^{\star} \\
147 \pm 7^{\star} \\
147 \pm 7^{\star}\end{array}$ & $\begin{array}{r}8.0 \pm 1.1^{\#} \\
15.5 \pm 2.3^{\#} \\
30.0 \pm 3.7^{\#}\end{array}$ & $\begin{array}{r}9.4 \pm 1.1^{\star \#} \\
18.1 \pm 2.1^{\star \#} \\
34.8 \pm 4.2^{\star \#}\end{array}$ \\
\hline
\end{tabular}

${ }^{*}$ Significantly different from other exercise intensity.

"Significantly different from other exercise duration.

IAT, individual anaerobic threshold; HR, heart rate. intensity $(P=0.037)$ of trial but no interaction $(P=0.574)$. All pre-exercise cTnI concentrations were below the URL, with the exception of one subject, who was slightly above the URL on two days. Post-exercise, there were no significant differences among the exercise trials in the percentage of subjects who exceeded the URL of cTnI (range: 0$9 \%$ ). The exercise-related increases in cTnI were independent of the age, training status, $\mathrm{VO}_{2 \max }$ and the other variables controlled in the study. In all exercise trials, the resting values of cTnI were significantly correlated with the post-exercise values $(r=0.45-0.86, P<0.05)$ (Fig. 2$)$, but were not associated with the delta change scores.

\section{Discussion}

This study demonstrates, for the first time, by controlled manipulation in the same cohort of endurance runners, the influence of exercise duration and intensity on post-exercise elevations in cardiac-specific biomarkers. The key finding was that exercise duration has a mediating effect on peak post-exercise concentrations of NT-proBNP and cTnI, whereas exercise intensity significantly influences only cTnI.

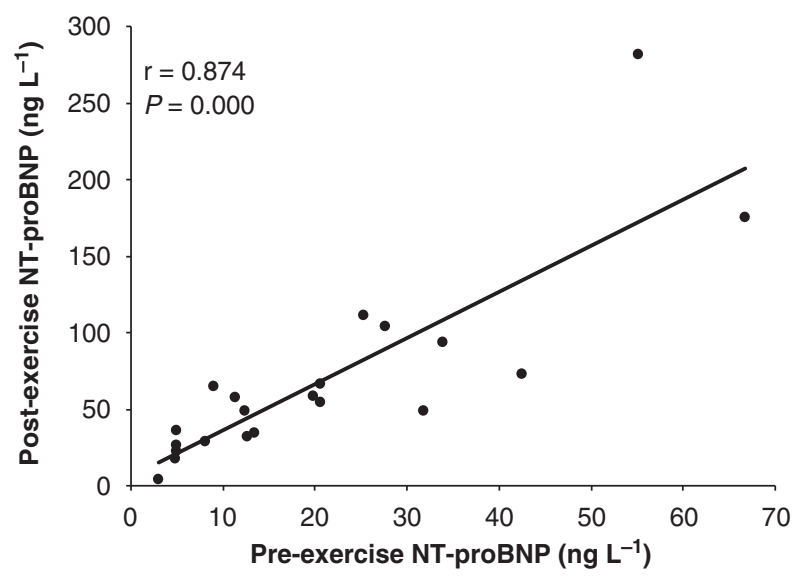

Fig. 1. Correlation between pre-exercise and post-exercise levels of $\mathrm{N}$-terminal pro-brain natiuretic peptide (NTproBNP) in a running trial of $180 \mathrm{~min}$ at $95 \%$ individual anaerobic threshold.

Table 2. NT-proBNP levels ( $\mathrm{ng} / \mathrm{L}$ ) before and after the exercise trials

\begin{tabular}{|c|c|c|c|c|c|c|}
\hline & \multicolumn{3}{|l|}{$85 \%$ IAT } & \multicolumn{3}{|l|}{$95 \%$ IAT } \\
\hline & Pre-exercise & 30 min post & $3 \mathrm{~h}$ post & Pre-exercise & 30 min post & $3 \mathrm{~h}$ post \\
\hline $\begin{array}{l}45 \mathrm{~min} \\
90 \mathrm{~min} \\
180 \mathrm{~min}\end{array}$ & $\begin{array}{l}27 \pm 26 \\
25 \pm 29 \\
23 \pm 25\end{array}$ & $\begin{array}{l}38 \pm 42 \\
42 \pm 38 \\
67 \pm 57\end{array}$ & $\begin{array}{l}43 \pm 47 \\
45 \pm 41 \\
63 \pm 54\end{array}$ & $\begin{array}{l}32 \pm 31 \\
28 \pm 27 \\
21 \pm 17\end{array}$ & $\begin{array}{l}43 \pm 46 \\
52 \pm 39 \\
65 \pm 63\end{array}$ & $\begin{array}{l}46 \pm 46 \\
51 \pm 37 \\
58 \pm 46\end{array}$ \\
\hline
\end{tabular}

Significant main effect for exercise duration but no significant interaction.

IAT, individual anaerobic threshold. 


\section{Serrano-Ostáriz et al.}

Table 3. $\mathrm{cTnl}(\mu \mathrm{g} / \mathrm{L})$ levels before and after the exercise trials

\begin{tabular}{|c|c|c|c|c|c|c|}
\hline & \multicolumn{3}{|l|}{$85 \%$ IAT } & \multicolumn{3}{|l|}{$95 \%$ IAT } \\
\hline & Pre-exercise & 30 min post & $3 \mathrm{~h}$ post & Pre-exercise & 30 min post & $3 \mathrm{~h}$ post \\
\hline $45 \mathrm{~min}$ & $0.007 \pm 0.01$ & $0.008 \pm 0.01$ & $0.009 \pm 0.01$ & $0.007 \pm 0.01$ & $0.008 \pm 0.01$ & $0.010 \pm 0.01$ \\
\hline $90 \mathrm{~min}$ & $0.009 \pm 0.01$ & $0.010 \pm 0.01$ & $0.009 \pm 0.01$ & $0.007 \pm 0.01$ & $0.008 \pm 0.01$ & $0.016 \pm 0.02$ \\
\hline $180 \mathrm{~min}$ & $0.008 \pm 0.01$ & $0.012 \pm 0.01$ & $0.011 \pm 0.01$ & $0.011 \pm 0.01$ & $0.017 \pm 0.02$ & $0.021 \pm 0.02$ \\
\hline
\end{tabular}

Significant main effect for exercise duration and intensity but no significant interaction.

IAT, individual anaerobic threshold.

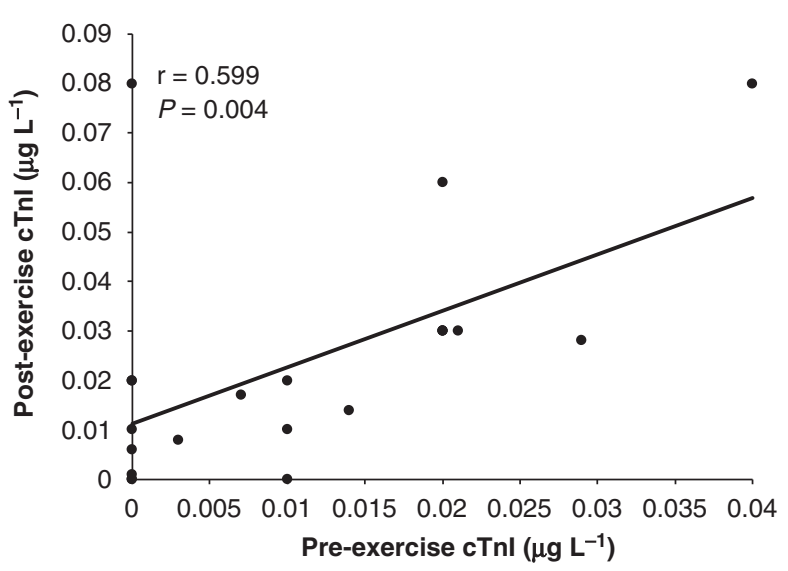

Fig. 2. Correlation between pre-exercise and post-exercise levels of cardiac troponin I (cTnI) in a running trial of $180 \mathrm{~min}$ at $95 \%$ individual anaerobic threshold.

An increase in the post-exercise NT-proBNP concentration with longer exercise bouts is not surprising when one considers that physiologically and pathologically BNP is elevated in response to volume overload and myocyte stretch (Shave et al., 2007a). Indirect support for the impact of exercise duration comes from data produced in ultra-endurance studies such that NT-proBNP concentrations after $180 \mathrm{~min}$ of running at $95 \%$ IAT were smaller than concentrations observed after a $230 \mathrm{~km}$ cycle race (Neumayr et al., 2005). Despite higher NT-proBNP values after the exercise trials at $95 \%$ IAT, these differences were not significant compared with the $85 \%$ IAT trial. This may reflect the small absolute and relative difference in exercise load between these two intensities. With a high inter-individual response to exercise (Neumayr et al., 2005), the small increase in ventricular load or stretch in the current design may be statistically underpowered to detect small differences. Again, of interest is the fact that values of the post-exercise cardiac biomarkers observed in the 90and 180 -min trials at $95 \%$ IAT were lower than the concentrations reported for competitive events such as the $21 \mathrm{~km}$ race (Vidotto et al., 2005; Tian et al., 2006) and a marathon (Neilan et al., 2006; Shave et al., 2007b), which, although could be influenced partially by a greater training status in our runners, may suggest that 95\% IAT underestimates the actual competitive running speed. Indeed, from within our own cohort, we have evidence from HR data collected during competitive running events that $95 \%$ IAT underpredicted maximal sustainable running $\mathrm{HR}$ in these athletes by 20 beats $/ \mathrm{min}$ in a $21 \mathrm{~km}$ race and by 13 beats/min in a marathon race. Thus, despite a lack of statistically significant difference in NT-proBNP data between running at $85 \%$ and $95 \%$ IAT, it would be too presumptive, at this stage, to suggest there is no broad effect of exercise intensity on this biomarker.

The fact that the cTnI values were increased in the longer as well as in the more intense bouts of exercise again likely reflects an impact of exercise volume and cardiac work. No previous studies have assessed cTn reponses in the same runners while systematically varying exercise duration and intensity but a recent meta-analysis (Shave et al., 2007b) reported that the occurrence of "positive" cTnT assays after prolonged exercise was mediated by exercise duration, with fewer responders after ultraendurance exercise (e.g. Ironman) compared with shorter endurance events (e.g. Marathons). These authors speculated that this could reflect a reduced exercise intensity sustained over more prolonged competitive events. Roth et al. (2007) further found no cTnT-positive rate in seven adult runners after a $216 \mathrm{~km}$ ultraendurance marathon on run. The negative effect of exercise duration on cTnT release was postulated as a result of the corresponding reduction in the exercise intensity and the resultant low stress placed on the cardiovascular system (Scharhag et al. 2008). This serves to indicate some of the problems in delineating the effects of exercise duration and intensity on responses seen in competitive running. It is pertinent to note that cTnI was also elevated from baseline after a shorter less intense exercise that may actually fit with our recent case-study finding of elevated cTnI after walking exercise (unpublished observations). The significant impact of exercise intensity on peak post-run cTnI in the current study may coincide with the increased level of free radicals that others have speculated may be involved in the mechanism of $\mathrm{cTn}$ release from cardiomyocytes post-exercise (Shave 
et al., 2007b). At present, this theory has no substantive evidence to support it but is worthy of an ongoing investigation.

Although we do not fully understand the physiological and/or the clinical impact of the cardiac-specific biomarker changes after prolonged exercise, the current data (in absolute and URL terms) suggest a minor and possibly physiological perturbation. With implications for the acute care management of endurance athletes, it is pertinent to note that only a relatively small percentage of runners demonstrated either NTproBNP or cTnI increases beyond their respective URL even in the exercise trial of the greatest duration and intensity $(<15 \%)$, although the current data may underpredict biomarker values seen after competitive events (Vidotto et al., 2005; Neilan et al., 2006; Tian et al., 2006; Shave et al., 2007b). A technical reason for the low biomarker concentrations and limited data exceeding URLs may relate to the frequency of blood sampling during and post-exercise (Middleton et al., 2008). Recently, Middleton et al. (2008) were the first to assay cTnT repeatedly during a laboratory treadmill-based marathon and multiple samples over the first $24 \mathrm{~h}$ of recovery. Interestingly, with a greater sampling frequency, this paper reported an elevation of cTnT in all subjects and thus it is clear that fewer samples would likely increase the chance of missing "true" peak concentrations and data exceeding URLs. Future work should attempt to replicate this finding and determine whether this response is mediated by subject- and exercise-related factors. The hypothetical model proposed by Whyte (2008), suggesting that a limit exists in the exercise duration and/or the intensity that determines the point of inflexion of the healthful or harmful effects of the physical activity on the heart, is interesting but remains unsupported by the current data. Our results suggest, like others (Middleton et al., 2008), that the increase in cardiac biomarkers is probably inherent to the physical activity, but that their magnitude is low or insignificant if the exercise intensity and duration are moderate.

It is interesting that the only factor that significantly predicted post-exercise values of NT-proBNP or cTnI was their respective pre-exercise values. Specifically, our results confirm for the NT-proBNP values those observed by Sahlén et al. (2008), and indicate for the first time, for the cTnI values, that exercise in runners with greater resting values induced a greater absolute increase in cardiac-specific biomarkers. This has been suggested previously for NT-proBNP, with possible mediation via increased age (Neumayr et al., 2005), although age was not a significant predictor in the current study. Given that the resting NT-proBNP data demonstrated high reproducibility even after a 3-year period (Sahlén et al., 2008), these results suggest a more complex interaction of baseline, prior exercise and exercise- related factors that mediate cardiac biomarker responses to prolonged exercise. In the general population, the baseline NT-proBNP value is influenced by age and sex (Olsen et al., 2008) while in recreational athletes, greater NT-proBNP levels at baseline have been associated weakly with increased LV mass index (Sahlén et al., 2008) and with age (König et al., 2003). Further exploratory research in a broad range of normal and athletic groups is suggested. In a similar way, this study demonstrated that the post-exercise levels of cTnI were associated with the baseline concentrations. As with NT-proBNP, these results suggest the importance of understanding what factors are associated with baseline levels of cTnI. Specifically, further analysis with highly sensitive assays in a broad range of normal and athletic populations would be useful.

The influence of gender on exercise-related changes in cardiac-specific biomarkers is an interesting point that is not clear at present. This aspect could not be addressed in our study due to the fact that only two female runners were recruited. Therefore, it cannot be excluded that the relationship between exercise duration and intensity on the appearance of cardiac biomarkers as well as its kinetic could be influenced by the gender.

In conclusion, the results of this study indicate that an exercise-induced increase in NT-proBNP is influenced more by exercise duration than intensity, while changes in cTnI are mediated by both in endurancetrained runners. The percentage of cases demonstrating post-exercise NT-proBNP and cTnI levels above their respective URLs was low, probably because the exercise volume in this repeated measures study was moderate. Further work looking at cTn appearance using the standard exercise prescription in healthy subjects and in cardiac patients may be useful.

\section{Perspectives}

In this study, we highlighted that exercise duration and intensity are factors associated with the release of cardiac biomarkers. These results are important to inform and educate those who may measure $\mathrm{cTn}$ in subjects who have performed recent bouts of physical exertion. Future work may develop this area by investigating cTn release and exercise (possibly influenced by duration and intensity) in healthy subjects and cardiac patients. Finally, this investigation prompts further research into the factors associated with the inter-subject variability in the baseline and exercise-related values of NT-proBNP and cTnI.

Key words: troponin I, NTpro-BNP, exercise duration, exercise intensity. 


\section{Serrano-Ostáriz et al.}

\section{References}

Al-Barjas M, Nair D, Ayrton P, Morris $\mathrm{R}$, Davar J. How can the role of $\mathrm{N}$ terminal pro B Natriuretic Peptide (NT-proBNP) be optimised in heart failure screening? A prospective obsevational comparative study. Eur Heart J Fail 2004: 3(Suppl. 1): 51.

Apple FS, Quist HE, Doyle PJ, Otto AP, Murakami MM. Plasma 99th percentile reference limits for cardiac troponin and creatine kinase MB mass for use with European Society of Cardiology/American College of Cardiology consensus recommendations. Clin Chem 2003: 49: 1331-1336.

George K, Whyte G, Stephenson C, Shave R, Dawson E, Edwards B, Gaze D, Collinson P. Postexercise left ventricular function and $\mathrm{cTnT}$ in recreational marathon runners. Med Sci Sports Exerc 2004: 36: 1709-1715.

Herrmann M, Scharhag J, Miclea M, Urhausen A, Herrmann W, Kindermann W. Post-race kinetics of cardiac troponin $\mathrm{T}$ and $\mathrm{I}$ and $\mathrm{N}$ terminal pro-brain natriuretic peptide in marathon runners. Clin Chem 2003: 49: 831-834.

König D, Schumacher YO, Heinrich L, Schmid A, Berg A, Dickhuth HH. Myocardial stress after competitive exercise in professional road cyclists. Med Sci Sports Exerc 2003: 35: 16791683.

La Gerche A, Connelly KA, Mooney DJ, Macisaac AI, Prior DL. Biochemical and functional abnormalities of left and right ventricular function after ultra-endurance exercise. Heart 2008: 94: 860-866.

Middleton N, George KP, Whyte GP, Gaze D, Collinson P, Shave R. Cardiac Troponin $\mathrm{T}$ release is stimulated by endurance exercise in healthy humans. J Am Coll Cardio 2008: 52: 1813-1814. Neilan TG, Januzzi JL, LeeLewandrowski E, Ton-Nu TT, Yoerger DM, Jassal DS, Lewandrowski KB, Siegel AJ, Marshall JE, Douglas PS, Lawlor D, Picard MH, Wood MJ. Myocardial injury and ventricular dysfunction related to training levels among nonelite participants in the
Boston marathon. Circulation 2006: 114: 2325-2333.

Neumayr G, Pfister R, Mitterbauer G, Eibl G, Hoertnagel H. Effect of competitive marathon cycling on plasma $\mathrm{N}$-terminal pro-brain natriuretic peptide and cardiac troponin $\mathrm{T}$ in healthy recreational cyclists. Am J Cardiol 2005: 96: $732-$ 735.

Olsen MH, Hansen TW, Christensen MK, Gustafsson F, Rasmussen S, Wachtell K, Ibsen H, Torp-Pedersen C, Hildebrandt PR. Cardiovascular risk prediction by $\mathrm{N}$-terminal pro brain natriuretic peptide and high sensitivity $\mathrm{C}$-reactive protein is affected by age and sex. J Hypertens 2008: 26: 26-34.

Rifai N, Douglas PS, O'Toole M, Rimm E, Ginsburg GS. Cardiac troponin T and I, echocardiographic [correction of electrocardiographic] wall motion analyses, and ejection fractions in athletes participating in the Hawaii Ironman Triathlon. Am J Cardiol 1999: 83: 1085-1089.

Roth HJ, Leithäuser RM, Doppelmayr H, Doppelmayr M, Finkernagel H, von Duvillard SP, Korff S, Katus HA, Giannitsis E, Beneke R. Cardiospecificity of the 3rd generation cardiac troponin $\mathrm{T}$ assay during and after a $216 \mathrm{~km}$ ultra-endurance marathon run in Death Valley. Clin Res Cardiol 2007: 96: 359-364.

Sahlén A, Winter R, Lind B, Jacobsen PH, Ståhlberg M, Marklund T, Fux T, Svensson J, Braunschweig F. Magnitude, reproducibility, and association with baseline cardiac function of cardiac biomarker release in long-distance runners aged $>$ or $=55$ years. Am J Cardiol 2008: 102: 218-222.

Scharhag J, Herrmann M, Urhausen A, Haschke M, Herrmann W, Kindermann W. Independent elevations of $\mathrm{N}$-terminal pro-brain natriuretic peptide and cardiac troponins in endurance athletes after prolonged strenuous exercise. Am Heart J 2005: 150: 1128-1134.

Scharhag J, Shave R, George K, Whyte G, Kindermann W. Exercise-induced increases in cardiac troponins in endurance athletes: a matter of exercise duration and intensity? Clin Res Cardiol 2008: 97: 62-63.

Scharhag J, Urhausen A, Schneider G, Herrmann M, Schumacher K, Haschke M, Krieg A, Meyer T, Herrmann W, Kindermann W. Reproducibility and clinical significance of exercise-induced increases in cardiac troponins and $\mathrm{N}$-terminal pro brain natriuretic peptide in endurance athletes.

Eur J Cardiovasc Prev Rehabil 2006: 13: 388-397.

Shave R, George K, Gaze D. The influence of exercise upon cardiac biomarkers: a practical guide for clinicians and scientists. Curr Med Chem 2007a: 14: 1427-1436.

Shave R, George KP, Atkinson G, Hart E, Middleton N, Whyte G, Gaze D, Collinson PO. Exercise-induced cardiac troponin $\mathrm{T}$ release: a meta-analysis. Med Sci Sports Exerc 2007b: 39: 2099 2106.

Stegmann H, Kindermann W, Schnabel A. Lactate kinetics and individual anaerobic threshold. Int J Sports Med 1981: 2: 160-165.

Tian Y, Nie J, Tong TK, Cao J, Gao Q, Man J, Shi Q, Liu W. Changes in serum cardiac troponins following a 21-km run in junior male runners. $\mathbf{J}$ Sports Med Phys Fitness 2006: 46: 481488.

Tulloh L, Robinson D, Patel A, Ware A, Prendergast C, Sullivan D, Pressley L. Raised troponin $\mathrm{T}$ and echocardiographic abnormalities after prolonged strenuous exercise - the Australian Ironman Triathlon. Br J Sports Med 2006: 40: 605-609.

Vidotto C, Tschan H, Atamaniuk J, Pokan R, Bachl N, Müller MM. Responses of N-terminal pro-brain natriuretic peptide (NT-proBNP) and cardiac troponin I (cTnI) to competitive endurance exercise in recreational athletes. Int J Sports Med 2005: 26: 645-650.

Whyte GP. Clinical significance of cardiac damage and changes in function after exercise. Med Sci Sports Exerc 2008: 40: 1416-1423. 